\title{
Spectral analysis of a standard test track profile during passage of an agricultural tractor
}

\author{
M. Cutini, ${ }^{1}$ R. Deboli, ${ }^{2}$ A. Calvo, ${ }^{3}$ C. Preti, ${ }^{2}$ M. Inserillo, ${ }^{2}$ C. Bisaglia ${ }^{1}$ \\ ${ }^{1}$ Consiglio per la Ricerca e la Sperimentazione in Agricoltura, Unità di Ricerca per l'Ingegneria \\ Agraria, Laboratorio di Treviglio, Treviglio (BG), Italy; ${ }^{2}$ Italian National Research Council - Institute \\ for Agricultural and Earthmoving Machines (IMAMOTER), Torino, Italy; ${ }^{3}$ DISAFA, University of \\ Turin, Grugliasco (TO), Italy
}

\begin{abstract}
National statistics on work safety are pointing out a decreasing trend about related injuries and fatalities but an increasing number of reports about professional diseases. In this frame are also considered the mechanical vibrations, in particular whole-body vibrations (WBV). This study aims to reproduce and analyse the vertical displacement of the wheel of an agricultural tractor during the passage on a standard surface (IS0 5008) for defining potential correlations between the surface contour and the effects on vehicle dynamic and driver comfort by analysis of the signals acting under the tractor tires. An agricultural tractor, in four setting conditions and four different forward speeds, was tested on an ISO
\end{abstract}

Correspondence: Maurizio Cutini, Consiglio per la Ricerca e la Sperimentazione in Agricoltura, Unità di Ricerca per l'Ingegneria Agraria, Laboratorio di Treviglio, via Milano 43, 24047 Treviglio (BG), Italy.

Tel./Fax.: +39.0363.49603.

E-mail: maurizio.cutini@entecra.it

Keywords: ISO 5008, tractor vibration, WBV

Contributions: the authors contributed equally.

Conflict of interests: the authors declare no potential conflict of interests.

Acknowledgements: This study was funded by the PRIN project (2009): "Analysis of the rollover and the vibration in the agricultural tractors with respect to current safety legislation", Italian Ministry of Education, University and Research (MIUR) and the VIBRA.M.AG. project (2005): "Valutazione e controllo delle vibrazioni nei sistemi meccanici agrari con nuovi metodi d'indagine basati su banco vibrante", Italian Ministry of Agricultural, Alimentary and Forestry Policies, (MiPAAF).

Conference presentation: this paper was presented at the $10^{\text {th }}$ AIIA Conference: "AIIA13 - Horizons in agricultural, forestry and biosystems engineering", Viterbo, University of Tuscia, Italy, on September 8-12, 2013.

Funding: this study was funded by the PRIN project (2009): "Analysis of the rollover and the vibration in the agricultural tractors with respect to current safety legislation", Italian Ministry of Education, University and Research (MIUR) and the VIBRA.M.AG. project (2005): "Valutazione e controllo delle vibrazioni nei sistemi meccanici agrari con nuovi metodi d'indagine basati su banco vibrante", Italian Ministry of Agricultural, Alimentary and Forestry Policies, (MiPAAF).

(C) Copyright M. Cutini et al., 2013

Licensee PAGEPress, Italy

Journal of Agricultural Engineering 2013; XLIV(s2):e145
5008 standard test track. The accelerations at the hubs of the tractor were acquired and subsequently reproduced on a four hydraulic actuators test bench, at CRA-ING laboratories, Treviglio, Italy. The analysis of the spectrums generated have shown that a roughness surface induces a transformation of the part of energy developed by the forward speed of the vehicle in vertical acceleration that excites the elastic parts (i.e. tires, suspensions). These phenomena seem to indicate that vehicle's vibration entity is due to the combination of surface roughness and forward speed as amplitude and to the elastic properties of the vehicle as frequency.

\section{Introduction}

National statistics on work safety are pointing out a decreasing trend about injuries and fatalities but an increasing number of reports about professional diseases. A mean value more has been observed of $36 \%$ in the last 5 years but data in agricultural environment are increased of $383 \%$ in the same period. It's difficult to associate these data specifically to some well identified causes but it is sure that the interest about the occupational diseases is increasing. In this frame are also considered the mechanical vibrations. In particular, wholebody vibrations (WBV) could affect an operator driving an agricultural tractor depending on intensity, duration and frequency.

European Parliament Directive 2002/44/EEC sets the minimum requirements for protection of workers from risks to their health and safety arising from exposure to mechanical vibrations; moreover, in 2008, Italy adopted a specific national regulation on safety (Decree Law n. 81/2008). Although most of the studies are directed to measure comfort (Deboli et al., 2010), vibration dumping and developing models, one of the most important parameter as the surface profile, is not analyzed as expected, above all for the difficult its standardisation and measurement.

Vibrations with frequency lower than $2 \mathrm{~Hz}$ can cause smaller and temporary effects like motion sickness, which anyway interfere with the desired development of the work activity and produce a remarkable discomfort. A long-term exposure to vibrations with frequency ranging from 2 to $20 \mathrm{~Hz}$ can cause severe disease, like degenerative pathologies of the spine (Chiang et al., 2006; Seidel and Heide, 1986).

The work has the goal to reproduce and analyse the vertical displacement of the wheel of an agricultural tractor during the passage on a standard surface (ISO 5008:2002) for defining potential correlations between the surface contour and the effects on vehicle dynamic and driver comfort.

\section{State of the art}

For agricultural tractors, considering normal conditions of use, 
irregularity of working terrains and forward speed are the most important causes of vibrations transmitted to the driver (Scarlett et al., 2007), on tool oscillations and impact on work quality (Bisaglia et al., 2006; Cutini et al., 2011).

For several years, tires have been the main element for attenuation of mechanical vibrations on agricultural tractors. Their effectiveness depends on factors such as eccentricity, load, resonance frequency, and elasticity characteristics (Nguyen and Hinaba, 2011; Sherwin et al. 2004; Park et al., 2004; Taylor et al., 2000). So, most of the studies have been directed to the tires' properties, dumping systems and/or their interaction.

However, as aforementioned, in agricultural machines an important factor characterizing the amplitude and frequency of vibrations is represented by the environment, in particular by the soil unevenness.

Soil unevenness has a stochastic character; its deformation has a nonlinear, visco-elastic-plastic behavior and its condition depends on a wide range of parameters (cultivation, cropping/tillage history, texture, organic residue, drainage conditions, etc.) so that it is almost impossible to standardize testing conditions in fields. For this reason, the experimental test has been carried out on the smoother ISO, $100 \mathrm{~m}$ track. To analyze the effect of surface outline on the vehicle body is necessary to obtain the displacement, or the accelerations, acting under the tires.

The most common existing approach (Anthonis, et al., 2007; Bisaglia, et al., 2006) consist in an iterative methodology. During the field test, the accelerations are measured at specific locations of the machine (usually at the hubs), then the machine is put on a test bench and the actuators (one for each tires) of the bench are driven in order to create, by a deconvolution method, input signals such that the sensor readings (one for each hubs) match with the measurements (accelerations) obtained in the field.

\section{Theoretical considerations}

An iterative deconvolution method is a computerized control technique that enables to duplicate, in the test laboratory, vehicle or component responses measured during field testing. The calculation of the control signals for the actuator of the test bench, called drive signals, is a multivariable tracking problem, currently solved with the so-called iterative deconvolution (ID) procedure (Soderling, et al., 1999). ID is an off-line iterative feed forward procedure where the drive signals are updated by the measured frequency response function matrix (FRF) of the test arrangement and the tracking errors obtained in the previous iteration. Several commercial versions of the algorithm were developed. During the laboratory tests the Remote Parameter Control (RPC®) software from MTS Systems Corporation has been used. The drive signals obtained with this procedure can be considered an approximation of the real field surfaces subject to deformations.

\section{Materials and methods}

An agricultural tractor, in four setting conditions and four different forward speed, was tested on smoother ISO 5008 standard test track presents at CNR IMAMOTER testing facilities, located at Pratofiorito (Candiolo, T0). The tractor's hubs accelerations were acquired and subsequently reproduced on a four hydraulic actuators test bench, at CRA-ING laboratories of Treviglio (BG).

The vertical displacement of the hydraulic actuators were driven, by specific electronics, for reproducing the profiles defined as the vertical input of the surfaces.
The condition adopted and the relevant test code are reported.

Mass:

- With ballast (_Z)

- Without ballast (_N)

Tires inflation pressure

- $80 \mathrm{kPa}($ (08)

- $\quad 160 \mathrm{kPa}\left(\_16\right)$

Forward speed

- $6 \mathrm{~km} / \mathrm{h}(6)$

- $10 \mathrm{~km} / \mathrm{h}($ (10)

- $12 \mathrm{~km} / \mathrm{h}\left({ }_{1}\right)$

- $\quad 14 \mathrm{~km} / \mathrm{h}($ _ 14)

Three repetitions were carried out for each tests. The sampling frequency was $1250 \mathrm{~Hz}$.

The accelerations at the hubs of the tractor were acquired and subsequently reproduced, as above reported, on the four hydraulic actuators test bench by the deconvolution method.

\section{Tested vehicle}

The tested agricultural vehicle is a medium-range tractor, with a four-wheel drive (4WD) transmission, engine with $89 \mathrm{~kW}$ rated power, a closed rubber-mounted cabin and a mechanical suspended seat. The most relevant data for the tests are reported in Table 1.

\section{The test track}

The ISO 5008 track (Figure 1) consists of two parallel strips suitably spaced for the wheel track of the tractor. The surface of each strip is formed of wooden slats $80 \mathrm{~mm}$ wide, each slat separated from the next by a gap of $80 \mathrm{~mm}$. Slats are sited firmly in a base framework. The surface of each track strip has been defined by the ordinates of elevation, with respect to a level base, listed in Tables of ISO 5008 .

\section{Operative conditions}

During the tests, the tractor ran at four forward speeds $(6,10,12$ and $14 \mathrm{~km} / \mathrm{h}$ ), with tires at two inflation pressures (80 and $160 \mathrm{kPa})$. All tests were performed in unballast and ballast conditions. In the ballast tests, an $800 \mathrm{~kg}$ ballast was connected at the rear three-point hitch and a $320 \mathrm{~kg}$ ballast at the front.

One experienced operator (70 kg mass, $180 \mathrm{~cm}$ height) carried out all the tests.

Table 1. Tractor characteristics.

\begin{tabular}{lccc} 
Item & Parameter & Unit/type & Value/type \\
Tractor & Power & $\mathrm{kW}$ & 89 \\
& Wheelbase & $\mathrm{mm}$ & 2467 \\
& Front width track & $\mathrm{mm}$ & 1700 \\
& Rear width track & $\mathrm{mm}$ & 1800 \\
& Front mass & $\mathrm{kg}$ & 2230 \\
& Rear mass & $\mathrm{kg}$ & 2960 \\
& Cab suspension & type & Rubber mounts \\
& Front axle suspension & type & None \\
& Seat suspension & type & Mechanical \\
Front tires & Overall size & ETRTO 2005 & $420 / 85 \mathrm{R} 24$ \\
& Treads & $\mathrm{n}$. & $22 \times 2$ \\
& Treads height & mm & $41^{*}$ \\
\hline Rear tires & Overall size & ETRTO 2005 & $460 / 85 \mathrm{R} 38$ \\
& Treads & $\mathrm{n}$. & $22 \times 2$ \\
& Treads height & mm & $42,5^{*}$
\end{tabular}

${ }^{*}$ Measured at $160 \mathrm{kPa}$ at the midpoint of two consecutive noses, medium value of three measurements. The value was the same between right and left. 
Acquisition times ranged between $59 \mathrm{~s}$ at $6 \mathrm{~km} / \mathrm{h}$ forward speed and $25 \mathrm{~s}$ at $14 \mathrm{~km} / \mathrm{h}$.

Each test was replicated three times.

\section{Four poster test bench}

The CRA-ING four-post test bench is specifically designed to test large and heavy vehicles up to $15 \mathrm{t}$ (Figure 2).

The test rig is composed of a seismic mass of $408 \mathrm{t}$ weight, isolated from the ground by means of pneumatic springs, supporting four servohydraulic actuators, articulated for wheel-base/track adjustment. On the top of actuators are fixed four plates $1000 \mathrm{~mm}$ diameter upon which the tires of the vehicle are placed. Are also present a power hydraulic and a control unit, including a computer-based controller and a data acquisition unit.

Each actuator is controlled in position (up to a frequency of $100 \mathrm{~Hz}$ and a peak-to-peak amplitude of $250 \mathrm{~mm}$ ) and excites one tire of the vehicle in vertical direction.

The displacements of the actuators are measured through linear variable differential transformer (LVDT) transducers, whose output signals are acquired and recorded.

\section{Measure instrumentation}

The vehicle was instrumented with a set of four piezo-electric monoaxial accelerometers (range $\pm 50 \mathrm{~g}$, sensitivity $100 \mathrm{mV} / \mathrm{g}$ ) to measure the wheel hubs vertical acceleration. The output accelerometer signals were sent to a signal conditioner (Rogadaq 16) and then to a heavy-duty personal computer (Panasonic CF29).

\section{Results}

The acceleration registered on the standard track were reproduced at the four poster test bench.

A mean value of the root mean square error (RMSE) was 20.

Graphic example are reported in Figures 3 and 4.

Figure 3 shows the spectrum of both the desired (_des) and the reproduced signal (_res) in the test condition at $10 \mathrm{~km} / \mathrm{h}$, without ballast, tire pressure of $80 \mathrm{kPa}$, rear left hub (RL).

Figure 4 shows the spectrums of both the desired (_des) and the reproduced signal (_res) in the test condition at $10 \mathrm{~km} / \mathrm{h}$, without ballast, tire pressure of $160 \mathrm{kPa}$, front left hub (FL).

The analysis of the spectrums shows that, in each test, there is an energy peak proportional, as amplitude, to the forward tractor speed correlated to the elastic properties of the front tires. This peak must has been considered as an effect due to the specified tire models and not to the surface type.

In each test there are energy peaks corresponding to the vibration modes of the cabin. These peaks must be considered as a side effect correlated to the dynamics of the vehicle and to the test conditions and not to the surface type.

It can also be seen that, regardless of the surface type, moving towards and increasing forward speeds there is a correspondent increase of the spectrum magnitude in the whole range of frequency.

The surface types show similar frequency spectrum shapes, regardless of the forward speed: the power spectral density is most relevant at the lower frequencies $(<3 \mathrm{~Hz})$; increasing frequency the spectrum magnitude rapidly decreases. Between $4 \mathrm{~Hz}$ and $10-12 \mathrm{~Hz}$ the spectral components are less relevant. Above $12 \mathrm{~Hz}$ the spectral components are negligible; over this frequency band the spectrum is flat and the signals can be considered "white".

Two auto spectral density spectrum (ASD) are reported as example in the $\mathrm{N} \_16$ setting: Figure 5 shows the mean value of the displacement of the two front plates and Figure 6 of the rear.

In the frame of the comfort analysis it must be considered that two filters have been applied to the spectrums of the plates' acceleration:

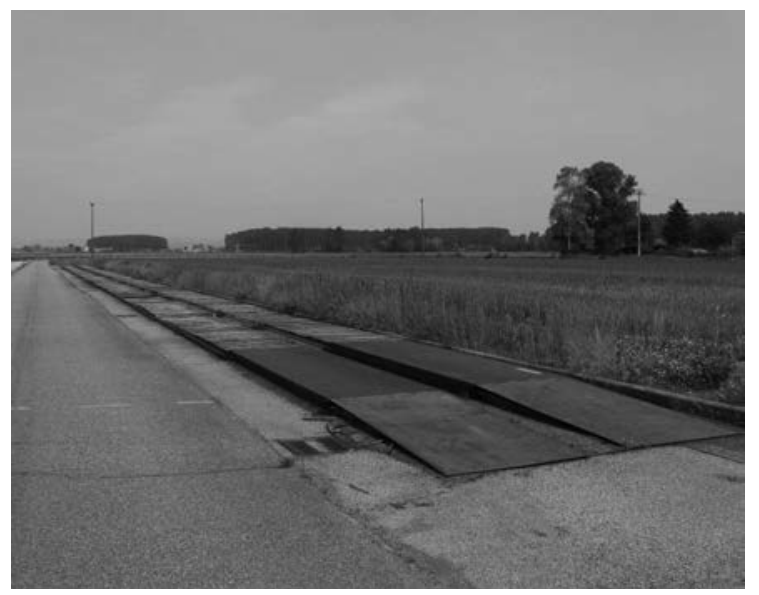

Figure 1. The standard test track.

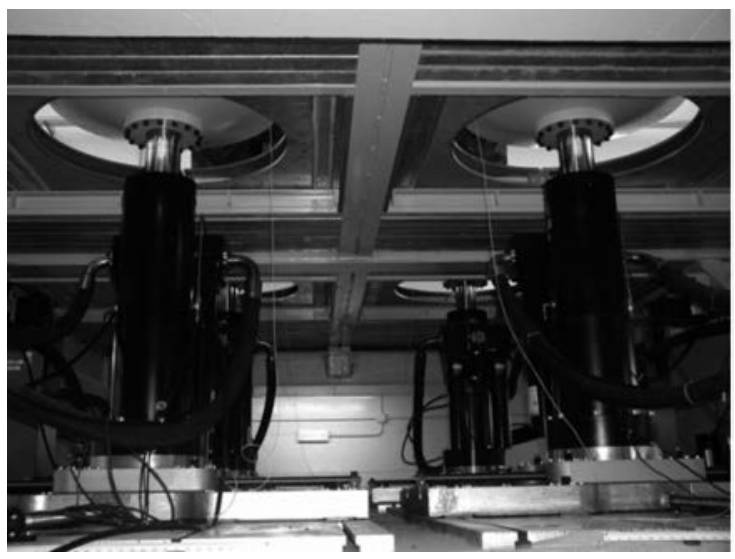

Figure. 2. The four poster test bench.

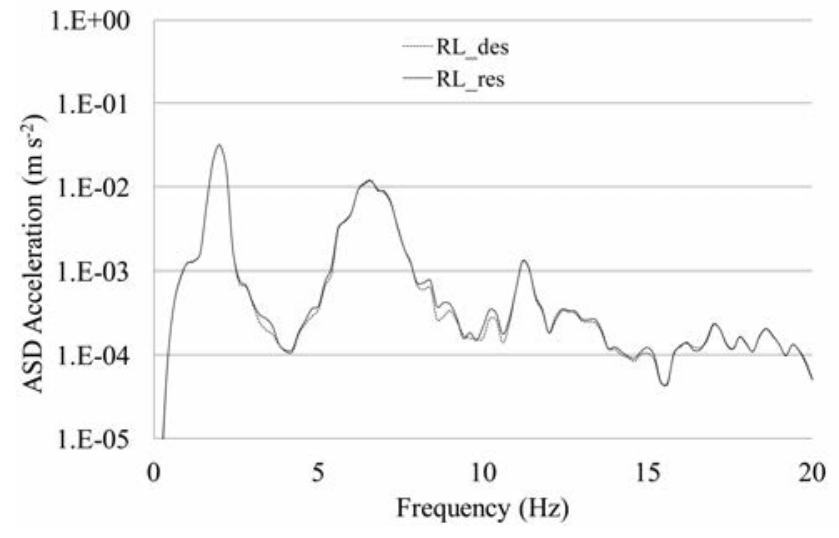

Figure 3. Example of reproducibility on the RL hub in R10_N08 condition. 
the filter related to the vehicle (tire, cab, seat) and the filter related to the procedure (ISO 2631).

The outcome is that the frequency band of interest results $0.6-12 \mathrm{~Hz}$ with a major contribute between $1-4 \mathrm{~Hz}$.

The interpretation of the results requires to consider the solicitation of the elastic part of the vehicle, as the change in rolling radius of the tires, when passing over a cleat. The forces induced depend from the surface forward curvature such as road unevenness. In the effort to evaluate the effect of rolling over an obstacle it is important to consider the increment in normal slope as height, curvature and length.

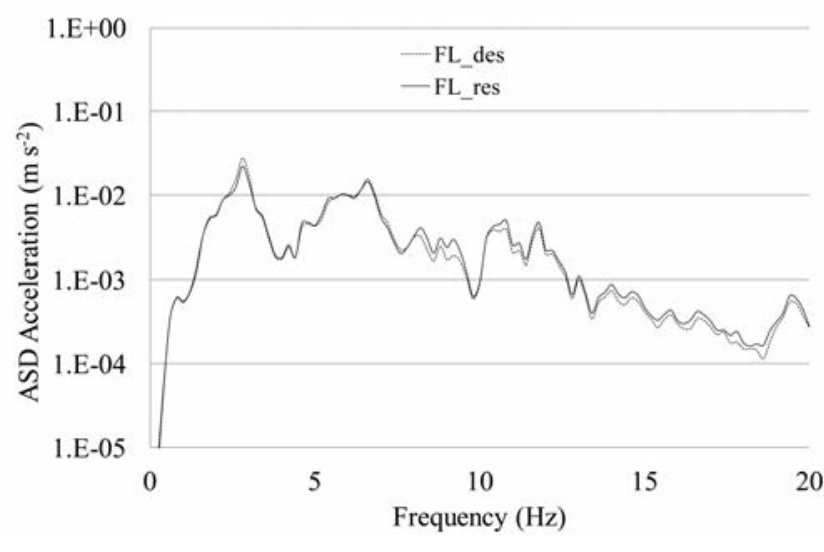

Figure 4. Example of reproducibility on the FL hub in R10_N16 condition.

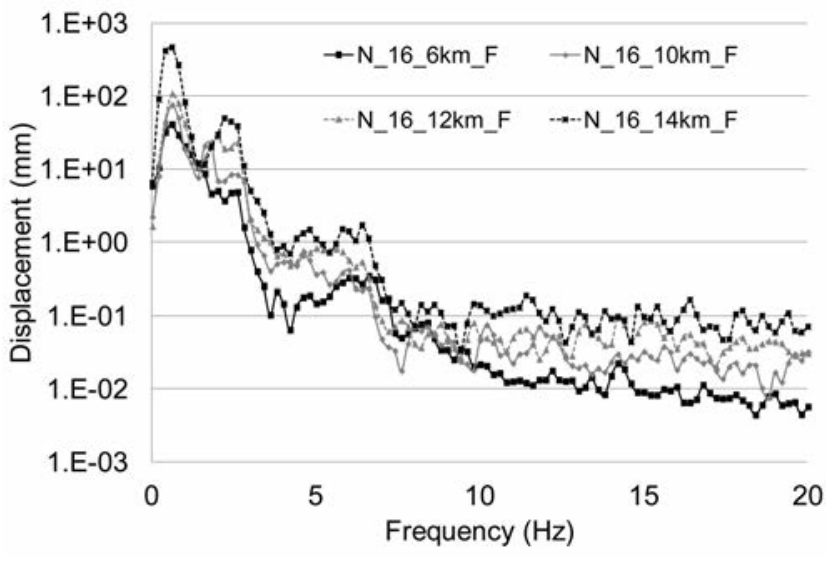

Figure. 5. ASD Spectrum of the settings N_16 on the front plates.

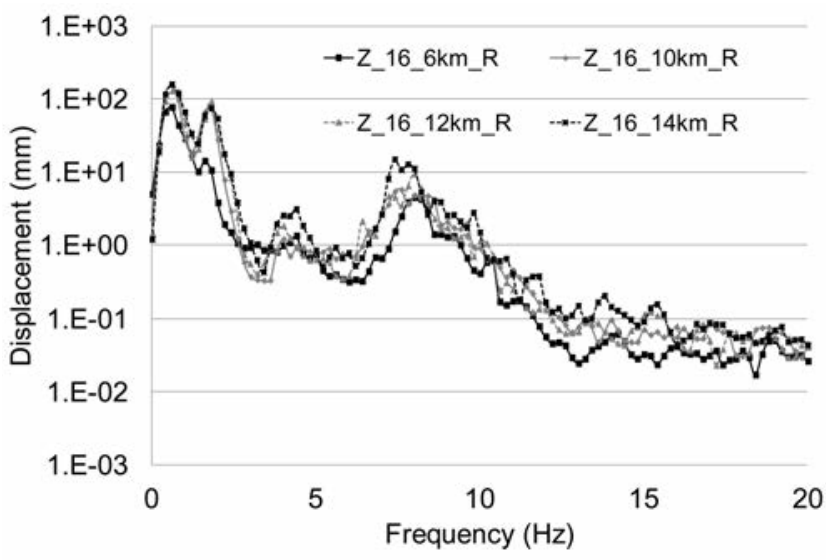

Figure. 6. ASD Spectrum of the setting $\mathrm{N}_{-} 16$ on the rear plates.

\section{Conclusions}

This first essay permitted to verify the functionality of the four hydraulic actuators test bench to reproduce vertical solicitations at the wheel hubs of a tractor when crossing the ISO 5008 track at different forward speeds, with different settings and different tires pressure.

The analysis of the spectrums of the data obtained both in the smooth track and in the test bench have shown that a roughness surface induces a transformation of the forward speed of the vehicle in vertical acceleration that excites the elastic parts (i.e. tires, suspensions, ...). These phenomena seem to indicate that vehicle's vibration entity is due to the combination of surface roughness and forward speed as amplitude and to the elastic properties of the elastic parts as frequency.

The comparison between the spectral power density of the accelerations of the wheel hubs achieved in the track with the same acquired in laboratory lead in new possibilities to redesign new artificial tracks to acquire vibration values over the tractor, which could convey to acceleration data at the operator seat.

\section{References}

Anthonis J., D. Vaes, K. Engelen, H. Ramon, J. Swevers 2007. Feedback Approach for Reproduction of Field Measurements on a Hydraulic Four Poster. Biosystems Engineering. 96(4): 435-445.

Bisaglia C., Cutini M., Gruppo G. 2006. Assessment of vibration reproducibility on agricultural tractors by a four poster test stand. Proc. XVI CIGR EurAgEng 2006. Bonn, Germany,1-6.

Chiang C. F., Liang C. C. 2006. A study on biodynamic models of seating human subjects exposed to vertical vibration. International Journal of Industrial Ergonomics. 36: 869-890.

Cutini M., Bisaglia C., Romano E. 2011. Measuring the radial eccentricity of agricultural tires for ride vibration assessment. Proc.39th Int. Symp. on Agr. Eng. Opatija, Croatia. 63-72.

Deboli R., Calvo A., Preti C. 2012. Transmissibility of agricultural tractors seats. Proc.Int. Conf. RagusaShwa. Ragusa, Italy. 368 - 374 .

Italian Decree n. 81 , Testo Unico in materia di tutela della salute e della sicurezza nei luoghi di lavoro, 9 April 2008

European Directives, 2002. Directive 2002/44/EC, Minimum health and safety requirements regarding the exposure of workers to the risks arising from physical agents (vibration), Official Journal, vols. L177, 06/07/2002, P. 0013-0020

International standards: ISO 5008: 2002. Agricultural wheeled tractors and field machinery - Measurement of whole-body vibration of the operator. International Organization for Standardization Publ., Geneva, Switzerland.

Nguyen V. N., Inaba S. 2011. Effects of tire inflation pressure and tractor velocity on dynamic wheel load and rear axle vibrations. J. of Terramechanics.48: 3-16.

Park S., Popov A.A., Cole D.J. 2004. Influence of soil deformation on offroad heavy vehicle suspension vibration. J. of Terramechanics. 41: 41-68.

Scarlett A. J., Price J. S., Stayner R. M. 2007. Whole body vibration: 
Evaluation of emissions and exposure levels arising from agricultural tractors. J. of Terramechanics. 44: 65-73.

Seidel H., Heide R. 1986. Long-term effects of whole-body vibration: a critical survey of the literature. Int. Arch. of Occ. and Env. Health. 58(1): 1-26.

Sherwin L. M., Owende P. M. 0., Kanali C. L., Lyons J., Ward S. M. 2004. Influence of tyre inflation pressure on whole-body vibrations trans- mitted to the operator in a cut-to-length timber. Applied Ergonomics. 35(3): 235-261.

Soderling, S., Sharp, M. Leser, C. 1999. Servo Controller Compensation Methods Selection of the Correct Technique for Test Applications. VII Int. MobilityTechnology Conf. Sao Paulo, Brazil: 30-35.

Taylor R.K., Bashford L.L., Schrock M.D. 2000. Methods for measuring vertical tire stiffness. Transactions of the ASAE. 43(6): 1415-1419. 